\title{
Cytological evaluation of breast lesions in symptomatic patients presenting to Kenyatta National Hospital, Kenya: a retrospective study
}

\author{
Ken Munene Nkonge ${ }^{1 *}$, Emily Adhiambo Rogena $^{2}$ Edwin Owino Walong ${ }^{2}$ and Dennis Karani Nkonge ${ }^{1}$
}

\begin{abstract}
Background: Palpable breast lump, breast pain, and nipple discharge are common symptoms of breast disease. Breast cytology (fine-needle aspiration, nipple discharge smear, and touch preparation) accurately identifies benign, atypical, and malignant pathological changes in breast specimens. This study aims to determine the types of breast lesions diagnosed by breast cytology and assess the clinical adequacy of narrative reporting of breast cytology results.
\end{abstract}

Methods: Medical records of 390 patients presenting to breast or general surgery clinics in Kenyatta National Hospital, Nairobi, Kenya, between January 2010 and March 2014 were evaluated retrospectively.

Results: Of the 390 diagnosed breast lesions, $89.7 \%(n=350)$ occurred in females, while $10.3 \%(n=40)$ occurred in males, giving rise to a female-to-male ratio of 8.8:1. Neoplastic breast lesions $(n=296)$ comprised $75.9 \%$, while non-neoplastic breast lesions $(n=94)$ comprised $24.1 \%$ of all diagnosed breast lesions. The neoplastic lesions were classified as $72.3 \%(n=214)$ benign and $27.7 \%(n=82)$ malignant, resulting in a benign-to-malignant ratio of 2.6:1. Fibroadenoma $(n=136)$ and gynecomastia $(n=33)$ were the most frequently diagnosed breast lesions for women and men, respectively.

Conclusions: Breast cytology effectively diagnosed neoplastic and non-neoplastic breast lesions. Neoplastic breast lesions occurred more frequently in women whereas non-neoplastic lesions occurred more frequently in men. To address the limitations associated with narrative reporting of breast cytology results, a synoptic reporting format incorporating the United Kingdom's National Health Service Breast Screening Programme's diagnostic categories (C1 to C5) is recommended for adoption by this hospital.

Keywords: Breast, Cytopathology, Fibroadenoma, Gynecomastia, Synoptic reporting

\section{Background}

Palpable breast lump, breast pain, and nipple discharge are common manifestations of benign, premalignant, or malignant lesions in the human mammary gland and surrounding tissues [1-4]. Techniques used to diagnose breast lesions include clinical breast examination, breast imaging, and breast cytology [2, 4]. Fine-needle aspiration cytology is the most reliable component of this triple test assessment of breast lesions due to its high

\footnotetext{
* Correspondence: ken.munene@students.uonbi.ac.ke

'School of Medicine, University of Nairobi, P.O. Box 19676, Nairobi, Kenya Full list of author information is available at the end of the article
}

sensitivity, specificity, negative predictive value, and positive predictive value $[3,5]$.

Malignant and benign breast diseases are prevalent in girls and women in Sub-Saharan Africa [6, 7] as exemplified by three studies from Kenyatta National hospital $(\mathrm{KNH})$, a tertiary referral and teaching hospital in Nairobi, Kenya. A histologic study of 1501 breast specimens conducted by Bjerregaard and Kung'u found that benign and malignant lesions accounted for $72.2 \%$ and $27.8 \%$ of the diagnosed breast lesions, respectively [8]. A retrospective study of 1172 patient records performed by Otieno et al. found that fibroadenoma (33.2 \%) and 
Table 1 Presenting complaints of study population $(n=390)$

\begin{tabular}{llll}
\hline Presenting complaint & Women & Men & Total \\
\hline Palpable breast lump & 337 & 40 & 377 \\
Nipple discharge & 29 & 0 & 29 \\
Breast pain & 19 & 8 & 27 \\
Skin changes & 22 & 0 & 22 \\
Palpable axillary lymph node(s) & 15 & 0 & 15 \\
Nipple retraction & 5 & 0 & 5 \\
Median duration (in months) & 11 & 4.5 & 8 \\
\hline
\end{tabular}

ductal carcinoma (17.4\%) were the most frequently diagnosed types of lesions and $98.9 \%$ of all breast lesions occurred in female patients [9]. Finally, a prospective cross-sectional study of 166 breast cancer patients conducted by Otieno et al. found that $98.8 \%$ of patients diagnosed with breast cancer were females and $24.1 \%$ of patients had been incorrectly reassured that their disease was benign prior to being diagnosed with breast cancer [10].

The primary objective of this study was to determine the type and sex-specific distribution of breast lesions diagnosed by cytological evaluation of breast specimens from patients presenting to $\mathrm{KNH}$ with breast complaints over a four year period. The secondary objective of this study was to evaluate the clinical adequacy of narrative reporting of breast cytology results.

\section{Methods}

Medical records in the form of breast cytology reports from 443 consecutive patients presenting to breast or general surgical clinics at $\mathrm{KNH}$ over the period of January 5, 2010 and March 6, 2014 with palpable breast lump, nipple discharge, breast pain, nipple retraction, skin changes, or axillary lymphadenopathy were accessed from the records department of KNH's cytology laboratory and examined for eligibility. Reports having patient age and sex, clinical summary, breast cytology sampling technique, microscopic findings, and conclusive breast cytology diagnosis were included in the study. Reports having major typographical errors, clinical history of breast cancer, cytological diagnosis of secondary breast diseases, and inconclusive breast cytology results were excluded from the study. A total of 390 breast cytology reports satisfied eligibility criteria. All data were analyzed using Microsoft Excel 2013 and results described using summary statistics. This single institution study was approved by the Kenyatta National Hospital/University of Nairobi Ethics and Research Committee (Ref: KNHERC/UA/189). The need for written or verbal informed consent was waived by the KNH-ERC.

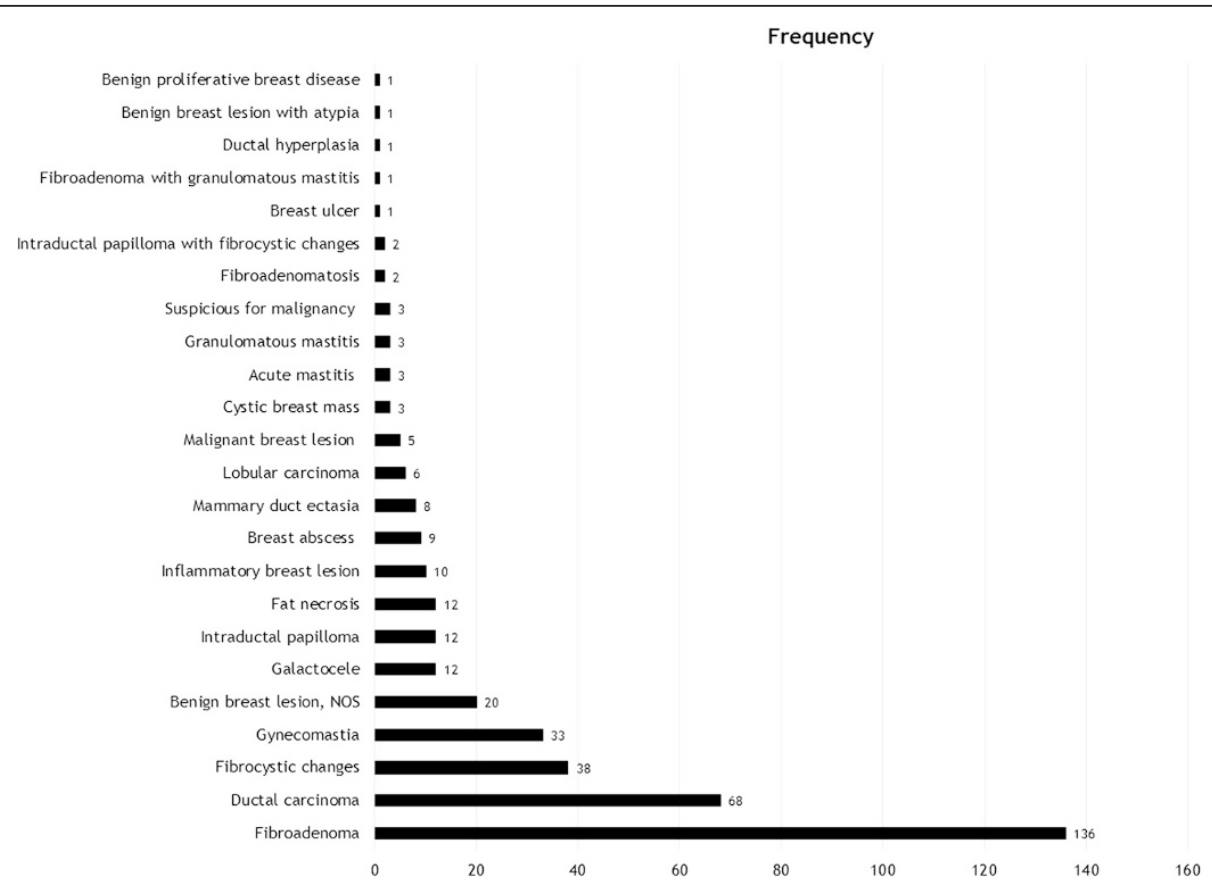

Fig. 1 Cytological profile of breast lesions diagnosed in women and men $(n=390)$. Bar chart represents the frequency distribution of all breast lesions diagnosed from January 2010 to March 2014. NOS: not otherwise specified 


\section{Results}

Presenting complaints and diagnosed breast lesions

The mean age of the evaluated patients was $36.0 \pm 16.7$ (range, 10-90) years and the sex-specific mean age was $34.6 \pm 16.2$ (range, 10-90) years for women and 48.6 \pm 16.2 (range, 15-78) years for men. Breast lesions were most frequently diagnosed in women aged $20-24$ years $(n=91)$ and $50+$ years $(n=65)$, and men aged $50+$ years $(n=25)$. The presenting complaints are summarized in Table 1. Palpable breast lump was the most common $(96.7 \% ; n=377)$ while nipple retraction was the least common $(1.3 \% ; n=5)$ presenting complaint. The median duration of presenting complaints in patients was 11 months for women and 4.5 months for men.

The frequency distribution of all diagnosed breast lesions is shown in Fig. 1. Fibroadenoma $(n=136)$ and fibrocystic changes $(n=38)$ were the most frequently diagnosed benign breast lesions whereas ductal carcinoma $(n=68)$ was the most frequently diagnosed malignant breast lesion. Other frequently diagnosed breast lesions included gynecomastia $(n=33)$, benign breast lesions, not otherwise specified $(n=20)$, galactocele $(n=12)$, intraductal papilloma $(n=12)$, and fat necrosis $(n=12)$.

\section{Types of diagnosed breast lesions and sex-specific distribution}

Of the 390 diagnosed breast lesions, $75.9 \% \quad(n=296)$ were neoplastic and $24.1 \%(n=94)$ were non-neoplastic. Of the neoplastic breast lesions, $72.3 \%(n=214)$ were benign and $27.7 \%(n=82)$ were malignant. Thus, the benign-to-malignant ratio was 2.6:1. Of the nonneoplastic breast lesions, $48.9 \%(n=46)$ were associated with inflammation whereas $51.1 \%(n=48)$ were not associated with inflammation.

The sex-specific distribution of breast lesions diagnosed by breast cytology (Table 2) shows that $98 \%$ of the neoplastic and $63.8 \%$ of the non-neoplastic breast lesions occurred in women. Fibroadenoma (38.9 \%), ductal carcinoma (18\%), and fibrocystic changes (10.9 \%) were the most frequently diagnosed breast lesions in women. Fibroadenoma affected women aged 10-57 years, ductal carcinoma affected women aged 21-90 years, and fibrocystic changes affected women aged 21-67 years. Lobular carcinoma affected women aged 37-83 years and accounted for $1.7 \%$ of the breast lesions diagnosed in women.

In men, $2 \%$ of the breast lesions were neoplastic whereas $36.2 \%$ were non-neoplastic. Gynecomastia (82.5\%) was the most frequent breast lesion in men and was diagnosed in men aged 17-67 years. Ductal carcinoma $(12.5 \%)$ was the only neoplastic breast lesion and was diagnosed in men aged $52-68$ years. Taken together,
Table 2 Sex-specific distribution of breast lesions diagnosed by breast cytology

\begin{tabular}{|c|c|c|c|}
\hline Cytological diagnoses & $\begin{array}{l}\text { Women } \\
\mathrm{n}(\%)\end{array}$ & $\begin{array}{l}\text { Men } \\
\text { n (\%) }\end{array}$ & $\begin{array}{l}\text { Total } \\
\text { n (\%) }\end{array}$ \\
\hline \multicolumn{4}{|l|}{ A. Neoplastic } \\
\hline Ductal carcinoma & $63(18 \%)$ & $5(12.5 \%)$ & $68(17.4 \%)$ \\
\hline Fibroadenoma & $136(38.9 \%)$ & $0(0 \%)$ & 136 (34.9\%) \\
\hline Fibrocystic changes & 38 (10.9\%) & $0(0 \%)$ & $38(9.7 \%)$ \\
\hline Benign breast lesion, NOS & $19(5.4 \%)$ & $1(2.5 \%)$ & $20(5.1 \%)$ \\
\hline Intraductal papilloma & $12(3.4 \%)$ & $0(0 \%)$ & $12(3.1 \%)$ \\
\hline Lobular carcinoma & $6(1.7 \%)$ & $0(0 \%)$ & $6(1.5 \%)$ \\
\hline Malignant breast lesion & $5(1.4 \%)$ & $0(0 \%)$ & $5(1.3 \%)$ \\
\hline Suspicious for malignancy & $3(0.9 \%)$ & $0(0 \%)$ & $3(0.8 \%)$ \\
\hline Fibroadenomatosis & $2(0.6 \%)$ & $0(0 \%)$ & $2(0.5 \%)$ \\
\hline $\begin{array}{l}\text { Intraductal papilloma with } \\
\text { fibrocystic changes }\end{array}$ & $2(0.6 \%)$ & $0(0 \%)$ & $2(0.5 \%)$ \\
\hline $\begin{array}{l}\text { Fibroadenoma with } \\
\text { granulomatous mastitis }\end{array}$ & $1(0.3 \%)$ & $0(0 \%)$ & $1(0.3 \%)$ \\
\hline Ductal hyperplasia & $1(0.3 \%)$ & $0(0 \%)$ & $1(0.3 \%)$ \\
\hline $\begin{array}{l}\text { Benign breast lesion with } \\
\text { atypia }\end{array}$ & $1(0.3 \%)$ & $0(0 \%)$ & $1(0.3 \%)$ \\
\hline $\begin{array}{l}\text { Benign proliferative breast } \\
\text { disease }\end{array}$ & $1(0.3 \%)$ & $0(0 \%)$ & $1(0.3 \%)$ \\
\hline \multicolumn{4}{|l|}{ B. Non-neoplastic } \\
\hline Gynecomastia & $0(0 \%)$ & $33(82.5 \%)$ & $33(8.5 \%)$ \\
\hline Galactocele & $12(3.4 \%)$ & $0(0 \%)$ & $12(3.1 \%)$ \\
\hline Fat necrosis & $12(3.4 \%)$ & $0(0 \%)$ & $12(3.1 \%)$ \\
\hline Breast abscess & $9(2.6 \%)$ & $0(0 \%)$ & $9(2.3 \%)$ \\
\hline Inflammatory breast lesion & $9(2.6 \%)$ & $1(2.5 \%)$ & $10(2.6 \%)$ \\
\hline Mammary duct ectasia & $8(2.3 \%)$ & $0(0 \%)$ & $8(2.1 \%)$ \\
\hline Acute mastitis & $3(0.9 \%)$ & $0(0 \%)$ & $3(0.8 \%)$ \\
\hline Cystic breast mass & $3(0.9 \%)$ & $0(0 \%)$ & $3(0.8 \%)$ \\
\hline Granulomatous mastitis & $3(0.9 \%)$ & $0(0 \%)$ & $3(0.8 \%)$ \\
\hline Breast ulcer & $1(0.3 \%)$ & $0(0 \%)$ & $1(0.3 \%)$ \\
\hline
\end{tabular}

$89.7 \%(n=350)$ of breast lesions occurred in females, while $10.3 \%(n=40)$ of breast lesions occurred in males, giving rise to a female-to-male ratio of $8.8: 1$.

\section{Clinical adequacy of narrative reporting of breast cytology results}

Results from the 390 breast cytology reports evaluated were reported in descriptive narrative format. Based on the findings from Abati and Simsir's review [11] of the 1996 National Cancer Institute Consensus Panel Criteria for optimal performance and reporting of breast fineneedle aspiration [12], breast cytology reports from $\mathrm{KNH}$ were found clinically inadequate and requiring improvement. All the reports lacked standardized diagnostic terminology and did not clearly report clinical 
and imaging findings, lesion localization technique, specimen adequacy, triple test assessment findings, and post-cytology recommendations. To address these limitations, a synoptic reporting format (Fig. 2) has been developed and is recommended for adoption by $\mathrm{KNH}$. The recommended synoptic reporting format clearly shows the clinical and imaging findings, lesion localization technique, triple test score, and post-cytology recommendations and also incorporates the National Health Service Breast Screening Programme's (NHSBSP) breast cytology diagnostic categories: inadequate $(\mathrm{C} 1)$, benign (C2), atypia probably benign (C3), suspicious of malignancy (C4), and malignant (C5) [13, 14]. Notably, integration of triple test findings to the recommended synoptic reporting format is expected to facilitate clinical decision-making by stratifying patients into three evidence-based groups [4, 15]: patients eligible for scheduled breast imaging follow-up based on triple test scores of 3-4, patients eligible for excisional biopsy and cytohistologic correlation based on triple test scores of

\section{Synoptic breast cytology report Day, Month, Year}

Presenting complaint

$\begin{array}{lll}\text { Breast lump } & \square & \text { Nipple retraction } \\ \text { Breast pain } & \square & \text { Skin changes } \\ \text { Nipple discharge } & \square \quad \text { Axillary lymphadenopathy }\end{array}$

Clinical and imaging findings

Breast examination: Normal / benign / suspicious / malignant Breast imaging: Normal / benign / suspicious / malignant

Location of lesion

Laterality: $\quad$ right breast / left breast / bilateral
UOQ $\square \quad$ UIQ $\square$
LOQ $\square$

\section{Localization technique}

Palpation $\square \quad$ Image-guided
Sampling technique
FNA $\square \quad$ Nipple discharge smear $\square$ Touch p
Specimen adequacy
Adequate $\square$
Few epithelial clusters
Moderate epithelial clusters
Abundant epithelial clusters
Diagnostic category
C1: inadequate
C2: benign
C3: atypia probably benign
C4: suspicious of malignancy
C5: malignant

\section{Microscopic description}

Fig. 2 Recommended synoptic reporting format for recording breast cytology results. The recommended synoptic reporting format consists of clinically relevant parameters in checklist form with minimal use of narrative and incorporates standardized diagnostic terminology. FNA: fine-needle aspiration; LIQ: lower inner quadrant; LOQ: lower outer quadrant; UIQ: upper inner quadrant; UOQ: upper outer quadrant 
$5-7$, and patients eligible for immediate surgical intervention or definitive therapy based on triple test scores of 8-9 and overall clinical impression.

\section{Discussion}

The primary objective of the present study was to determine the type and distribution of breast lesions diagnosed by breast cytology in Kenyan patients presenting to a tertiary referral hospital over a four year period. Of the total diagnosed breast lesions, $72.3 \%$ were benign, which is in agreement with findings by Bjerregaard and Kung'u [8] and Panjvani et al. [16]. Fibroadenoma was the most frequently diagnosed lesion in pre-menopausal women, while gynecomastia was the most frequently diagnosed lesion in men, consistent with both prospective and retrospective studies from Uganda [7], India [16], and Pakistan [17]. Palpable breast lump (377 patients) was the most common presenting complaint, which is consistent with previous findings in Kenya [10] and elsewhere $[2,17,18]$. Nipple discharge (29 patients) was the second most common presenting complaint. Although nipple discharge is often suggestive of breast malignancy when unilateral, bloody, or associated with a breast lump [1, 19, 20], its diagnostic value is controversial [2, 19-22]. Consequently, more studies are needed to establish the suitability of triple test assessment for diagnostic evaluation of patients presenting with nipple discharge. Finally, despite the consistency of present findings with existing literature, the prevalence of breast diseases in Kenya may be underestimated by the retrospective study design. Population-based studies are therefore needed to fully characterize the epidemiology of breast diseases in Kenya.

The secondary objective of this study was to assess the clinical adequacy of narrative reporting of breast cytology results. All of the breast cytology reports evaluated in this study used a non-standardized descriptive narrative format instead of a standardized checklistbased synoptic format [23]. Synoptic reporting of pathology results is gaining acceptance in Asia and North America. A synoptic report was recently developed and used in Japan to accurately report breast cytology results in a series of 3439 cases [24]. Additionally, a cancer reporting project conducted in Ontario, Canada by Srigley et al. found that a province-wide implementation of a synoptic reporting format generated more complete reports and led to increased rates of cancer reporting [25]. Our findings alongside those from other investigators suggest that evidence-based synoptic reporting combined with active monitoring of results may be superior to traditional narrative reporting. Therefore, adoption of the recommended synoptic reporting format by $\mathrm{KNH}$ is expected to enhance the clinical utility of diagnostic breast cytology and promote standardization of breast pathology practices in Kenya.

\section{Conclusions}

This study found that breast cytology effectively diagnosed neoplastic and non-neoplastic breast lesions. Neoplastic breast lesions occurred more frequently in women, while non-neoplastic lesions occurred more frequently in men. To address the limitations associated with narrative reporting of breast cytology results, $\mathrm{KNH}$ should adopt the recommended synoptic reporting format.

\begin{abstract}
Abbreviations
KNH: Kenyatta National Hospital; KNH-ERC: Kenyatta National Hospital/ University of Nairobi Ethics and Research Committee; NHSBSP: National Health Service Breast Screening Programme.
\end{abstract}

\section{Competing interests}

The authors declare no financial or non-financial competing interests.

\section{Authors' contributions}

EOW and KMN conceived of the study and its design. KMN and DKN collected data, analyzed and interpreted results, prepared figures and tables, undertook literature review, and drafted the manuscript. EAR and EOW critically reviewed the manuscript. All authors have read and approved of the final manuscript.

\section{Author details}

${ }^{1}$ School of Medicine, University of Nairobi, P.O. Box 19676, Nairobi, Kenya. ${ }^{2}$ Department of Human Pathology, School of Medicine, University of Nairobi, P.O. Box 19676, Nairobi, Kenya.

Received: 19 December 2014 Accepted: 12 December 2015

Published online: 15 December 2015

\section{References}

1. Barry M. Nipple discharge. In: Walker K, Hall D, Hurst JW, editors. Clinical methods: the history, physical, and laboratory examinations. 3rd ed. Boston: Butterworths; 1990. p. 820-1.

2. Salzman B, Fleegle S, Tully AS. Common breast problems. Am Fam Physician. 2012;86:343-9.

3. Ngotho J, Githaiga J, Kaisha W. Palpable discrete breast masses in young women: two of the components of the modified triple test may be adequate. S Afr J Surg. 2013;51:58-60.

4. Morris A, Pommier RF, Schmidt WA, Shih RL, Alexander PW, Vetto JT. Accurate evaluation of palpable breast masses by the triple test score. Arch Surg. 1998;133:930-4.

5. Muchiri LW, Penner DW, Adwok J, Rana FS. Role of fine-needle aspiration biopsy in the diagnosis of breast lumps at the Kenyatta National Hospital. East Afr Med J. 1993;70:31-3.

6. Edmund DM, Naaeder SB, Tettey Y, Gyasi RK. Breast cancer in Ghanaian women: what has changed? Am J Clin Pathol. 2013;140:97-102.

7. Okoth C, Galukande M, Jombwe J, Wamala D. Benign proliferative breast diseases among female patients at a sub-saharan Africa tertiary hospital: a cross sectional study. BMC Surg. 2013;13:9.

8. Bjerregaard B, Kung'u A. Benign breast lesions in Kenya: a histological study. East Afr Med J. 1992;69:231-5.

9. Otieno ES, Kimende SK, Micheni JN. The pattern of breast diseases at Kenyatta National Hospital. Annals African Surgery. 2008;2:97-101.

10. Otieno ES, Micheni JN, Kimende SK, Mutai KK. Delayed presentation of breast cancer patients. East Afr Med J. 2010;87:147-50.

11. Abati A, Simsir A. Breast fine needle aspiration biopsy: prevailing recommendations and contemporary practices. Clin Lab Med. 2005;25:631-54.

12. National Cancer Institute Fine-Needle Aspiration of Breast Workshop Subcommittees. The uniform approach to breast fine-needle aspiration biopsy. Diagn Cytopathol 1997, 16: 295-311.

13. Cytology Subgroup of the National Coordinating Committee for Breast Cancer Screening Pathology. Guidelines for cytology procedures and 
reporting in breast cancer screening. Sheffield: NHS Cancer Screening Programme; 2001. Publication No 50.

14. Kocjan G, Bourgain C, Fassina A, Hagmar B, Herbert A, Kapila K, et al. The role of breast FNAC in diagnosis and clinical management: a survey of current practice. Cytopathology. 2008;19:271-8.

15. Wai CJ, Al-Mubarak G, Homer MJ, Goldkamp A, Samenfeld-Specht M, Lee Y, et al. A modified triple test for palpable breast masses: the value of ultrasound and core needle biopsy. Ann Surg Oncol. 2013;20:850-5.

16. Panjvani SI, Parikh BJ, Parikh SB, Chaudhari BR, Patel KK, Gupta GS, et al. Utility of fine needle aspiration cytology in the evaluation of breast lesions. J Clin Diagn Res. 2013;7:2777-9.

17. Aslam HM, Saleem S, Shaikh HA, Shahid N, Mughal A, Umah R. Clinicopathological profile of patients with breast diseases. Diagn Pathol. 2013;8:77.

18. Walker S, Hyde C, Hamilton W. Risk of breast cancer in symptomatic women in primary care: a case-control study using electronic records. Br J Gen Pract. 2014;64:e788-93.

19. Montroni I, Santini D, Zucchini G, Fiacchi M, Zanotti S, Ugolini G, et al. Nipple discharge: is its significance as a risk factor for breast cancer fully understood? Observational study including 915 consecutive patients who underwent selective duct excision. Breast Cancer Res Treat. 2010;123:895-900.

20. Gupta RK, Gaskell D, Dowle CS, Simpson JS, King BR, Naran S, et al. The role of nipple discharge cytology in the diagnosis of breast disease: a study of 1948 nipple discharge smears from 1530 patients. Cytopathology. 2004;15:326-30.

21. Lang JE, Kuerer HM. Breast ductal secretions: clinical features, potential uses, and possible applications. Cancer Control. 2007;14:350-9.

22. Dolan RT, Butler JS, Kell MR, Gorey TF, Stokes MA. Nipple discharge and the efficacy of duct cytology in evaluating breast cancer risk. Surgeon. 2010;8:252-8.

23. Casati B, Haugland HK, Barstad GM, Bjugn R. Factors affecting the implementation and use of electronic templates for histopathology cancer reporting. Pathology. 2014;46:165-8.

24. Tsuchiya S, Akiyama F, Moriya T, Tsuda H, Umemura S, Katayama Y, et al. A new reporting form for breast cytology. Breast Cancer. 2009;16:202-6.

25. Srigley JR, McGowan T, Maclean A, Raby M, Ross J, Kramer S, et al. Standardized synoptic cancer pathology reporting: a population-based approach. J Surg Oncol. 2009:99:517-24.

\section{Submit your next manuscript to BioMed Central and we will help you at every step:}

- We accept pre-submission inquiries

- Our selector tool helps you to find the most relevant journal

- We provide round the clock customer support

- Convenient online submission

- Thorough peer review

- Inclusion in PubMed and all major indexing services

- Maximum visibility for your research

Submit your manuscript at www.biomedcentral.com/submit 